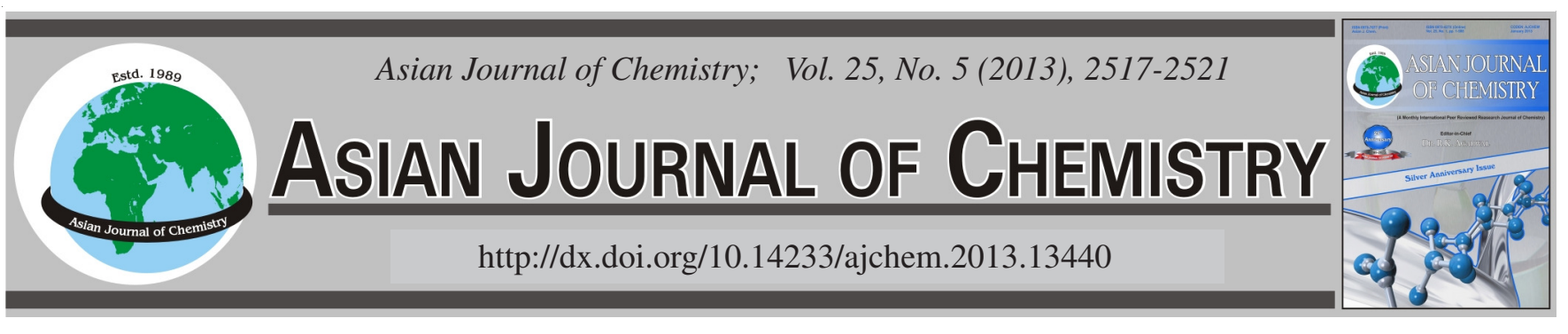

\title{
Pharmacokinetic Interaction Between Polyphyllin II and Hyperoside Extracts of Rhizoma Paridis and Hypericum Perforatum After Oral Administration in Beagle Dogs
}

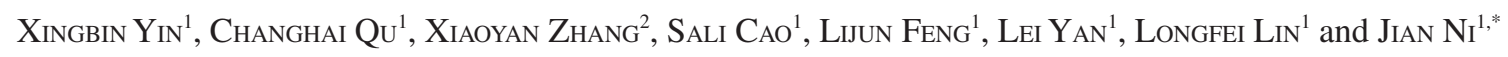

${ }^{1}$ School of Chinese Materia Medica, Beijing University of Chinese Medicine, Beijing 100102, P.R. China

${ }^{2}$ Department of Pharmaceutics, Beijing Institute of Pharmacology and Toxicology, Beijing 100850, P.R. China

*Corresponding author: Fax: +86 10 84738611; Tel: +86 10 84738607; E-mail: njtcm@263.net

(Received: 13 January 2012;

Accepted: 12 November 2012)

AJC-12392

A rapid and specific RP-HPLC-UV method was developed for the analysis of polyphyllin II and hyperoside in beagle dog plasma. The analysis was carried out on a Diamonsil $\mathrm{C}_{18}(2)$ reversed-phase column $(250 \times 4.6 \mathrm{~mm}, 5 \mathrm{~mm})$ by isocratic elution with acetonitrile and $0.1 \%$ phosphoric acid (50: 50, v/v). The flow rate was $1.0 \mathrm{~mL} / \mathrm{min}$ and the detection wavelength was set at $203 \mathrm{~nm}$ and $360 \mathrm{~nm}$. Linear responses were obtained for polyphyllin II ranging from 3.3333 to $100 \mu \mathrm{g} / \mathrm{mL}$ and hyperoside ranging from 2 to $60 \mu \mathrm{g} / \mathrm{mL}$. The intra and interday precisions (RSDs) were less than 9.23 and $9.24 \%$ with the accuracy (\%) ranging from 89.67 to $107.25 \%$. The extraction recovery ranged from 84.97 to $91.32 \%$ with RSD less than $7.381 \%$. Stability studies showed that two compounds were stable in analytical process. In the pharmacokinetic interaction study, present findings indicate that polyphyllin II and hyperoside have a clear effect on the pharmacokinetic behaviour.

Key Words: Polyphyllin II, Hyperoside, Pharmacokinetics interaction, RP-HPLC, Beagle dog plasma.

ᄂ - - - - - - - - - - - - - - - - - - - - - - - -

\section{INTRODUCTION}

Rhizoma Paridis (named chonglou in Chinese) have been used as a traditional Chinese medicine to treat inflammation, fracture and convulsion ${ }^{1}$ for centuries. According to their chemical structures, the major bioactive constituents in Rhizoma Paridis are the polyphyllin compounds, which belong to a group of saponin. The major active component is polyphyllin II (Fig. 1 A). Pharmacological tests have revealed that polyphyllin II possesses a variety of pharmacological activities including antiviral, anticancer, antifertility and sedative activity $^{2-4}$. The highly potent pharmacological activities of polyphyllin II warrant further studies on its efficacy.

Hypericum perforatum (named guanye jinsitao in Chinese) is a well-known traditional Chinese medicine for the treatment of depression and $\operatorname{arthralgia}^{1}$. Hyperoside (Fig. 1 B) is the major component from hypericum perforatum has been shown to exhibit analgesia activity, protective effects against myocardial ischemia, cerebral ischemia-reperfusion injury and cerebral infarction $^{5,6}$.

Pharmacokinetic study plays a pivotal role in drug discovery and development. Several methods have been described for the determination of polyphyllin II and hyperoside ${ }^{7-9}$. However, to our best of knowledge, no paper has been developed and validated to study the pharmacokinetics of polyphyllin II and hyperoside neither have the pharmacokinetics interaction been investigated.

In this study, we have developed a rapid, specific and sensitive RP-HPLC-DAD method for the quantification of polyphyllin II and hyperoside in beagle dog plasma. The method was used to study the pharmacokinetic interactions of polyphyllin II and hyperoside after oral administration of polyphyllin II and hyperoside extracts.

\section{EXPERIMENTAL}

Polyphyllin II, hyperoside and hederagenin (Fig. 1 C) were purchased from the National Institute for Food and Drug Control (Beijing, China). Polyphyllin II extracts (purity is $9.55 \%$ ) and hyperoside extracts (purity is $6.01 \%$ ) were supplied by Beijing University of Chinese Medicine (Beijing, China). Acetonitrile (HPLC-grade) and methanol (HPLC-grade) were purchased from Fisher (USA). Phosphoric acid (HPLC-grade) was obtained from Beijing Reagent Co. Ltd. (Beijing, China). Other regents were all of analytical grade. All regents were passed through a $0.22 \mu \mathrm{m}$ membrane filter before use to purify.

The chromatographic analyses were performed using an Agilent HPLC system (Agilent, USA) consisting of a solvent gradient delivery pump and an diode-array detector. Chromatographic separations were achieved using a Diamonsil $\mathrm{C}_{18}$ (2) reversed-phase column $(250 \times 4.6 \mathrm{~mm} ; 5 \mathrm{~mm}$; Dikma 
<smiles>CC1CCC2(OC1)OC1CC3C4CC=C5CC(OC6OC(CO)C(OC7OC(CO)C(O)C7O)C(OC7OC(C)C(O)C(O)C7O)C6O)CCC5(C)C4CCC3(C)C1C2C</smiles><smiles>C=C(O)/C=C(\C)c1oc2cc(O)c(O)cc2c(=O)c1O[C@@H]1O[C@H](CO)[C@@H](O)[C@H](O)[C@H]1O</smiles>

Hyperoside

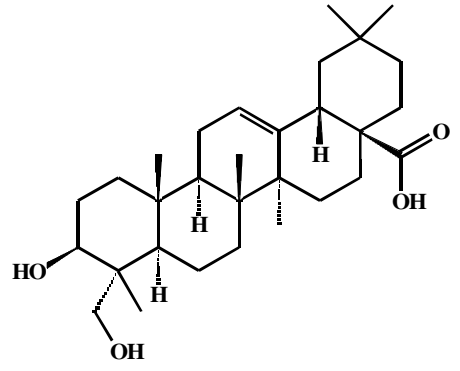

Hederagenin

Fig. 1. Chemical structures of polyphyllin II, hyperoside and hederagenin

Technologies, Beijing, China). The mobile phase used for the separation of Polyphyllin II and hyperoside in plasma samples consisted of acetonitrile and $0.1 \%$ phosphoric acid (50: $50, \mathrm{v} /$ v) delivered at $1.0 \mathrm{~mL} / \mathrm{min}$ flow rate. The polyphyllin II's detection wavelength was set at $203 \mathrm{~nm}$ and hyperoside's detection wavelength was set at $360 \mathrm{~nm}$. All measurements were performed at $37^{\circ} \mathrm{C}$ and the injection volume was $30 \mu \mathrm{L}$.

Male beagle dogs $(12.2 \pm 1.0 \mathrm{~kg})$ were purchased from the Animal Center of Beijing Institute of Pharmacology and Toxicology (Beijing, China). They were kept in an airconditioned animal quarters with free access to food and water for 7 days before starting the experiment. This study was performed according to the European community guidelines for the use of experimental animals.

Preparation of standards and quality control samples: Stock solutions of polyphyllin II and hyperoside were both prepared in methanol at concentrations of $600 \mu \mathrm{g} / \mathrm{mL}$. The stock solution of $200 \mu \mathrm{g} / \mathrm{mL}$ of internal standard was prepared in methanol and then further diluted with methanol to prepare the working internal standard solution containing $2 \mu \mathrm{g} / \mathrm{mL}$ of internal standard. All solutions were stored at $4{ }^{\circ} \mathrm{C}$. Calibration samples for polyphyllin II were prepared in blank dog plasma at concentrations of 6.67, 33.33, 66.67, 100, 166.67 and 200 $\mu \mathrm{g} / \mathrm{mL}$. Calibration samples for hyperoside were prepared in blank dog plasma at concentrations of 2, 5, 10,20, 40 and $60 \mu \mathrm{g} / \mathrm{mL}$.

The quality control samples were prepared at low (4.49 $\mu \mathrm{g} / \mathrm{mL}$ or $1.99 \mu \mathrm{g} / \mathrm{mL})$, medium $(26.01 \mu \mathrm{g} / \mathrm{mL}$ or $10.00 \mu \mathrm{g} /$ $\mathrm{mL})$ and high $(49.99 \mu \mathrm{g} / \mathrm{mL}$ or $49.97 \mu \mathrm{g} / \mathrm{mL})$ concentrations in the same way as the plasma samples for calibration and quality control samples were stored at $-20^{\circ} \mathrm{C}$ until analysis. The internal standard stock solution was prepared with methanol at concentrations of $0.5 \mathrm{mg} / \mathrm{mL}$.

Plasma sample preparation: An aliquot of $0.5 \mathrm{~mL}$ of plasma sample in a $5 \mathrm{~mL}$ plastic tube was mixed with 1.98 $\mathrm{mL}$ methanol and $20 \mu \mathrm{L}$ internal standard working solution $(2 \mu \mathrm{g} / \mathrm{mL})$. The tube was vortex-mixed for $1 \mathrm{~min}$ and centrifuged at $12000 \mathrm{rpm}$ for $10 \mathrm{~min}$. The supernatant was then transferred into another $5 \mathrm{~mL}$ plastic tube and evaporated to dryness under a gentle stream of nitrogen at $40^{\circ} \mathrm{C}$. The residue was reconstituted in $200 \mu \mathrm{L}$ solution consisting of methanol and centrifuged at $12000 \mathrm{rpm}$ for $5 \mathrm{~min}$. The supernatant was then injected into the HPLC system for analysis.

\section{Assay validation:}

Specificity: The specificity of the method was investigated by comparing chromatograms of blank plasma obtained from six beagle dogs The endogenous interference was assessed by comparing chromatograms of blank dog plasma, dog plasma sample spiked with polyphyllin II, hyperoside and internal standard $(2 \mu \mathrm{g} / \mathrm{mL})$ and plasma sample after oral administration of polyphyllin II and hyperoside extracts.

Calibration curves were prepared by assaying standard plasma samples at seven concentrations over the range of $6.6667-200 \mu \mathrm{g} / \mathrm{mL}$ for polyphyllin II and $2-60 \mu \mathrm{g} / \mathrm{mL}$ for hyperoside. The linearity of each calibration curve was determined by plotting the peak area ratios of analyte: internal standard $v s$. polyphyllin II or hyperoside concentration in beagle dog plasma. The linearity of the calibration curve was evaluated by linear regression analysis and the minimally acceptable correlation coefficient $\left(\mathrm{r}^{2}\right)$ was 0.99 or greater.

Precision and accuracy: The precision and accuracy of this method were determined with quailty control samples at low, medium and high concentration levels. To determine intra-day precision and accuracy, the assays were determined in the same day by analyzing five replicates of each concentration level. To determine inter-day precision and accuracy, the assays were determined on five continual days by analyzing three replicates of each concentration level. The precision was expressed as relative standard deviation (RSD \%) and the accuracy as the relative error (RE \%).

Recovery: The extraction recovery of polyphyllin II or hyperoside from plasma was determined at three concentration levels $(5,25$ and $50 \mu \mathrm{g} / \mathrm{mL}$ for polyphyllin II, 2,10 and $50 \mu \mathrm{g} /$ $\mathrm{mL}$ for hyperoside ) of quality control samples by comparing mean peak area of three extracted quality control samples with those of unextracted solutions (three replications for each concentration). The ratio was used to evaluate the matrix effect. The matrix effect of internal standard was evaluated using the same procedure.

Stability: Quality control samples of three concentration levels were subjected to three conditions, including kept at room temperature for $12 \mathrm{~h}$ (short-term stability, which exceeded the routine preparation time of samples), stored at $-20{ }^{\circ} \mathrm{C}$ for 30 days (long-term stability,) and after three freeze-thaw cycles (-20 ${ }^{\circ} \mathrm{C} /$ room temperature). 

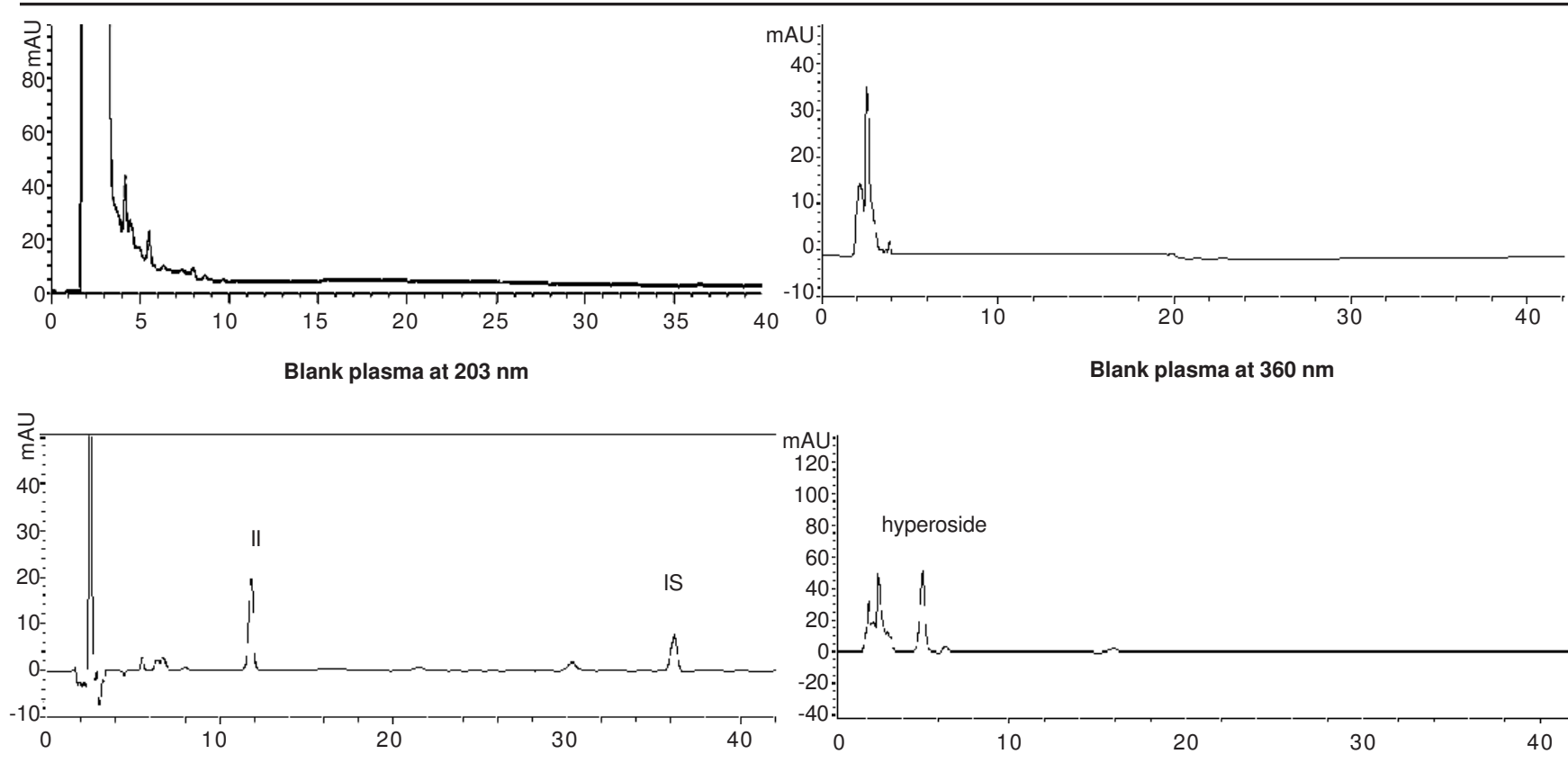

Blank plasma spiked with polyphyllin II and IS at $203 \mathrm{~nm}$
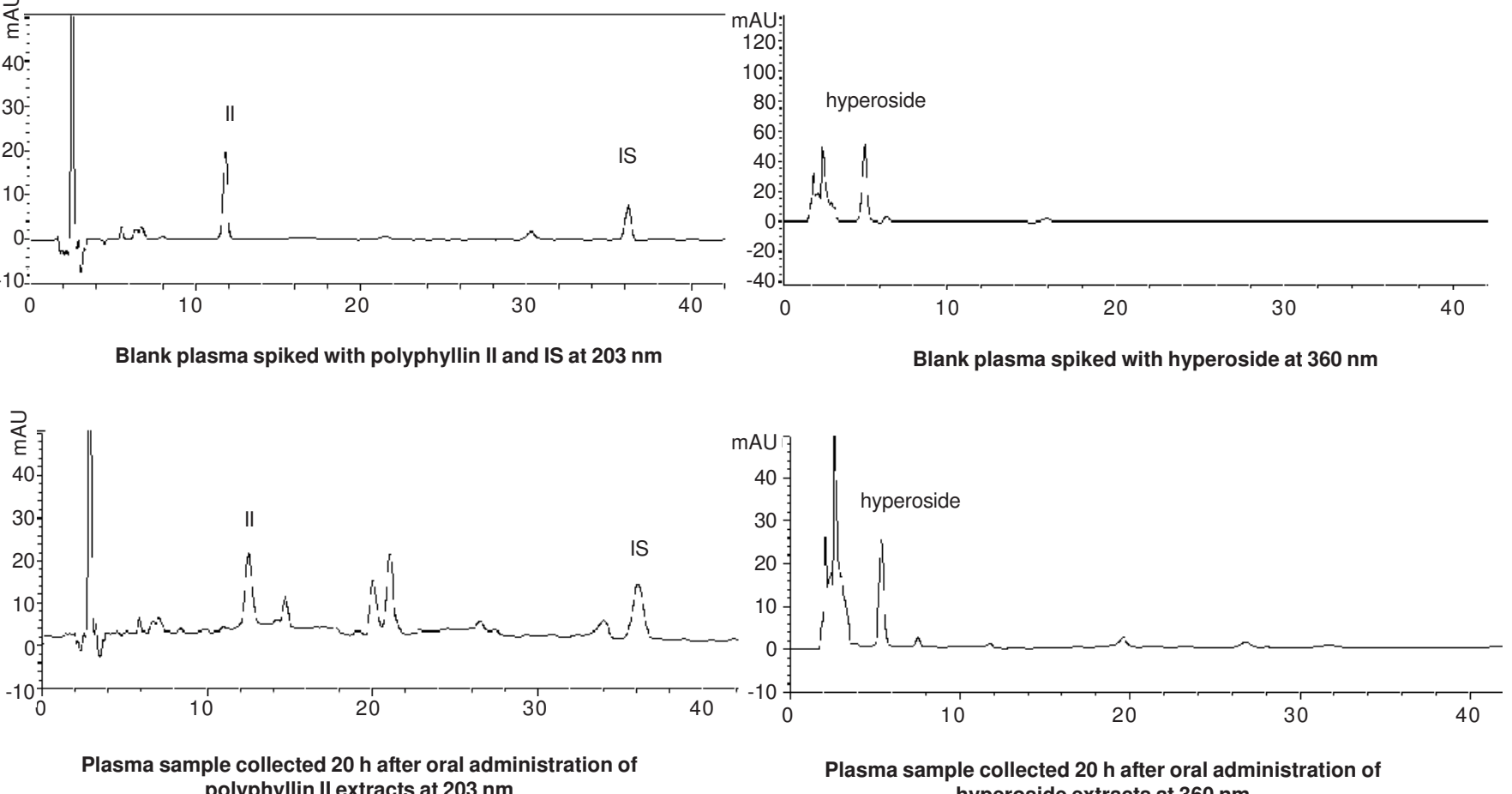

Plasma sample collected $20 \mathrm{~h}$ after oral administration of polyphyllin II extracts at $203 \mathrm{~nm}$

hyperoside extracts at $360 \mathrm{~nm}$

Fig. 2. Typical chromatograms of beagle dog plasma

Pharmacokinetic study: Six male beagle dogs were fast for $12 \mathrm{~h}$ and then polyphyllin II extracts was given orally as capsule at a dose of $2.23 \mathrm{~g}$ containing $21.28 \mathrm{mg}$ polyphyllin II. Blood samples $(0.5 \mathrm{~mL})$ were collected from the femoral vein of dogs in their front legs before administration and after that at $0.5,1,2,3,4,6,8,12$ and $24 \mathrm{~h}$. The blood samples were immediately centrifuged at 4,000 rpm for $10 \mathrm{~min}$ to separate out plasma and stored at $-20{ }^{\circ} \mathrm{C}$ until analysis.

After a week, the six male beagle dogs were fast for $12 \mathrm{~h}$ and then hyperoside extracts was given orally as capsule at a dose of $2.23 \mathrm{~g}$ containing $14.4 \mathrm{mg}$ hyperoside. The collection and preparation of plasma sample were in the same way as the polyphyllin II.

Statistical analysis: All the values were expressed as means standard deviation (SD). The pharmacokinetic parameters were analyzed using Kinetica 4.4 software (Thermo Scientific, USA).

\section{RESULTS AND DISCUSSION}

\section{Assay validation}

Specificity: The study confirm the specificity of this method. Fig. 2 shows the chromatographic profiles of blank plasma, blank plasma spiked with polyphyllin II, hyperoside and internal standard and plasma obtained $20 \mathrm{~h}$ after oral administration of polyphyllin II and hyperoside extracts at 203 or $360 \mathrm{~nm}$. As shown in Fig. 2, polyphyllin II, hyperoside and internal standard were detected with excellent resolution, the retention time was 12.11 (at $203 \mathrm{~nm}$ ), 4.65 (at $360 \mathrm{~nm}$ ) and 34.52 (at $203 \mathrm{~nm}$ ) min and no interfering peaks were observed in the blank plasma and in all samples tested.

Linearity and sensitivity: The linear response was obtained by plotting peak area ratios of polyphyllin II or hyperoside to the internal standard (y), vs. the plasma concentration of polyphyllin II or hyperoside (x). Typical equations for the calibration curves were: $\mathrm{y}=0.0016 \mathrm{x}-0.0057, \mathrm{r}=$ 0.9987 for polyphyllin II and $\mathrm{y}=0.5003 \mathrm{x}-0.3902, \mathrm{r}=0.9994$ for hyperoside. Linear responses were obtained for polyphyllin II ranging from 3.3333 to $100 \mu \mathrm{g} / \mathrm{mL}$ and hyperoside ranging from 2 to $60 \mu \mathrm{g} / \mathrm{mL}$.

Precision and accuracy: Table- 1 shows the intra-day and inter-day precision and accuracy. Polyphyllin II's intraday precision ranged from 4.55 to $9.23 \%$ and the interday precision ranged from 3.23 to $9.24 \%$, while the intra-day accuracy was 91.19-105.03\% and the inter-day accuracy was 89.67$107.25 \%$. Hyperoside's intra-day precision ranged from 2.07 


\begin{tabular}{|c|c|c|c|c|c|c|c|}
\hline \multirow[b]{3}{*}{ Compound } & \multicolumn{6}{|c|}{$\begin{array}{l}\text { TABLE- } 1 \\
\text { PRECISION AND ACCURACY FOR THE DETERMINATION OF POLYPHYLLIN II AND HYPEROSIDE } \\
\text { IN BEAGLE DOG PLASMA (INTRA-DAY: } \mathrm{n}=5 \text {; INTERDAY: } \mathrm{n}=5 \text { SERIES PER DAY, } 3 \text { DAYS) }\end{array}$} & \\
\hline & \multirow{2}{*}{$\begin{array}{c}\text { Nominal } \\
\text { concentration } \\
(\mu \mathrm{g} / \mathrm{mL})\end{array}$} & \multicolumn{3}{|c|}{ Intraday } & \multicolumn{3}{|c|}{ Interday } \\
\hline & & $\begin{array}{c}\text { Measured concentration } \\
(\mu \mathrm{g} / \mathrm{mL})\end{array}$ & $\begin{array}{l}\text { Precision } \\
(\text { RSD \%) }\end{array}$ & $\begin{array}{c}\text { Accuracy } \\
(\%)\end{array}$ & $\begin{array}{c}\text { Measured concentration } \\
(\mu \mathrm{g} / \mathrm{mL})\end{array}$ & $\begin{array}{l}\text { Precision } \\
(\text { RSD \%) }\end{array}$ & $\begin{array}{l}\text { Accuracy } \\
\text { (RSD \%) }\end{array}$ \\
\hline \multirow{3}{*}{ Polyphyllin II } & 4.39 & $4.00 \pm 0.21$ & 5.25 & 91.19 & $3.94 \pm 0.13$ & 3.23 & 89.67 \\
\hline & 9.01 & $9.46 \pm 0.87$ & 9.23 & 105.03 & $9.66 \pm 0.89$ & 9.24 & 107.25 \\
\hline & 26.04 & $25.77 \pm 1.17$ & 4.55 & 98.95 & $25.43 \pm 1.47$ & 5.80 & 97.67 \\
\hline \multirow{3}{*}{ Hyperoside } & 1.99 & $1.93 \pm 0.05$ & 2.45 & 96.82 & $1.89 \pm 0.05$ & 2.61 & 94.81 \\
\hline & 10.00 & $9.62 \pm 0.46$ & 4.80 & 96.23 & $9.72 \pm 0.19$ & 1.94 & 97.23 \\
\hline & 49.97 & $49.22 \pm 1.02$ & 2.07 & 98.49 & $48.79 \pm 0.91$ & 1.86 & 97.63 \\
\hline
\end{tabular}

to $4.80 \%$ and the interday precision ranged from 1.86 to $2.61 \%$, while the intraday accuracy was 96.23-98.49\% and the inter-day accuracy was 94.81-97.63\%. These results indicated an acceptable precision and accuracy of the present method for determination of polyphyllin II and hyperoside in beagle dog plasma.

Recovery: The extraction recovery determined for polyphyllin II and hyperoside is shown in Table-2. The average recovery for polyphyllin II and hyperoside ranged from 84.97 to $90.35 \%$ and from 89.85 to $91.32 \%$, respectively. These results indicated that the method has high extraction recovery.

TABLE-2

MEAN RECOVERY OF POLYPHYLLIN II AND HYPEROSIDE IN BEAGLE DOG PLASMA ( $\%$, mean $\pm \mathrm{SD}, \mathrm{n}=3)$

\begin{tabular}{lccc}
\hline Compound & $\begin{array}{c}\text { Nominal concentration } \\
(\mu \mathrm{g} / \mathrm{mL})\end{array}$ & $\begin{array}{c}\text { Recovery }(\%, \\
\text { mean } \pm \mathrm{SD}, \mathrm{n}=3)\end{array}$ & $\begin{array}{c}\mathrm{RSD} \\
(\%)\end{array}$ \\
\hline \multirow{3}{*}{ Polyphyllin II } & 4.39 & $84.97 \pm 4.51$ & 5.246 \\
& 9.01 & $90.35 \pm 2.20$ & 2.387 \\
& 26.04 & $90.16 \pm 5.00$ & 5.550 \\
\hline \multirow{3}{*}{ Hyperoside } & 1.99 & $90.12 \pm 4.97$ & 5.515 \\
& 10.00 & $91.32 \pm 6.74$ & 7.381 \\
& 49.97 & $89.85 \pm 4.71$ & 5.242 \\
\hline
\end{tabular}

Stability: Table-3 summarizes the results of short-term, long-term and freeze-thaw stabilities of polyphyllin II and hyperoside in plasma and post-preparation stability. The high stability property of polyphyllin II and hyperoside in dog plasma showed that the samples were stable in the preparation and analytical processes.

Pharmacokinetic study: In the present study, the method described above was applied to the analysis of plasma samples obtained from dogs administered orally with polyphyllin II and hyperoside extracts, which respectively contain $21.28 \mathrm{mg}$ polyphyllin II and $14.4 \mathrm{mg}$ hyperoside. The mean plasma concentration of polyphyllin II and hyperoside $(n=6) v s$. time profile is shown in Fig. 3 and the main pharmacokinetic parameters, as derived from these data, are summarized in Table- 4 .

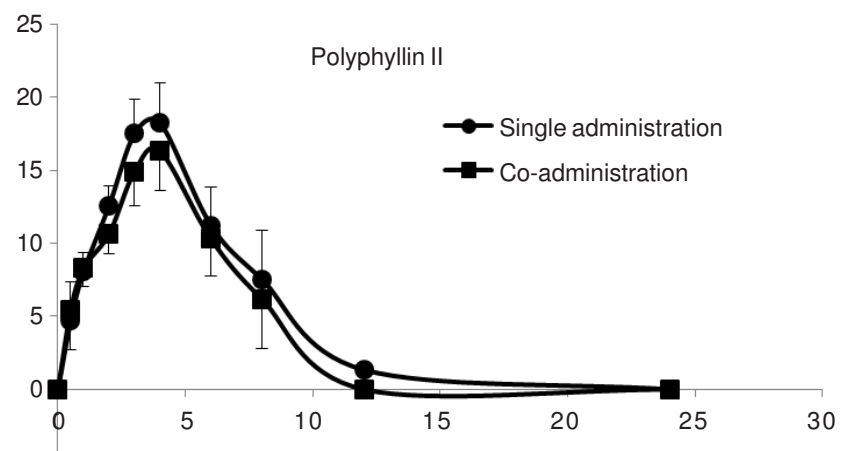

$-5$

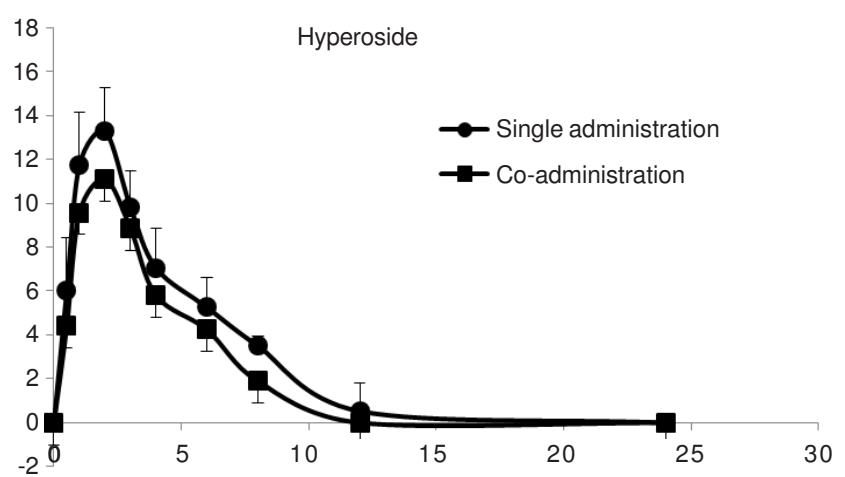

Fig. 3. Mean $( \pm \mathrm{SD})$ plasma concentration-time profiles of polyphyllin II and hyperoside after single oral administration and coadministration of polyphyllin II and hyperoside extracts

After single administration, polyphyllin II plasma concentration reached a maximum at $3.67 \pm 0.52 \mathrm{~h}$ after administration with an average $C_{\max }$ of $19.47 \pm 2.65 \mu \mathrm{g} / \mathrm{mL}$. The $T_{1 / 2}$ was calculated to be $4.43 \pm 2.60 \mathrm{~h}$. The area under the curve $\left(\mathrm{AUC}_{0-\infty}\right)$ was $151.38 \pm 46.57(\mathrm{~h} \mu \mathrm{g} / \mathrm{mL})$. The mean values of $\mathrm{K}_{\mathrm{e}}$ was $0.19 \pm$ $0.08 \mathrm{~h}^{-1}$ and MRT was $8.10 \pm 3.47 \mathrm{~h}$. After co-administration, polyphyllin II plasma concentration reached a maximum at 3.83 $\pm 0.41 \mathrm{~h}$ with an average $\mathrm{C}_{\max }$ of $16.30 \pm 2.69 \mu \mathrm{g} / \mathrm{mL}$. The $\mathrm{T}_{1 / 2}$ was calculated to be $3.77 \pm 1.67 \mathrm{~h}$. The area under the curve $\left(\mathrm{AUC}_{0-\infty}\right)$ was $128.45 \pm 35.30(\mathrm{~h} \mu \mathrm{g} / \mathrm{mL})$. The mean values of $\mathrm{K}_{\mathrm{e}}$ was $0.21 \pm 0.07 \mathrm{~h}^{-1}$ and MRT was $7.13 \pm 2.24 \mathrm{~h}$.

TABLE-3

STABILITY OF POLYPHYLLIN II AND HYPEROSIDE IN BEAGLE DOG PLASMA AT THREE QUALITY CONTROL LEVELS (n = 5)

\begin{tabular}{l|ccc|ccc}
\hline \multirow{3}{*}{ Stability } & \multicolumn{3}{|c|}{ Polyphyllin II } & \multicolumn{3}{c}{ Hyperoside } \\
\cline { 2 - 7 } & \multicolumn{3}{|c|}{ Accuracy $($ mean $\pm \mathrm{SD})$} & \multicolumn{3}{c}{ Accuracy $(\mathrm{mean} \pm \mathrm{SD})$} \\
\cline { 2 - 7 } & $5(\mu \mathrm{g} / \mathrm{mL})$ & $100(\mu \mathrm{g} / \mathrm{mL})$ & $250(\mu \mathrm{g} / \mathrm{mL})$ & $2(\mu \mathrm{g} / \mathrm{mL})$ & $10(\mu \mathrm{g} / \mathrm{mL})$ & $50(\mu \mathrm{g} / \mathrm{mL})$ \\
\hline 12 h at room temperature & $103.24 \pm 2.23$ & $100.23 \pm 4.33$ & $103.23 \pm 2.22$ & $93.35 \pm 6.31$ & $95.22 \pm 6.23$ & $100.32 \pm 6.21$ \\
30 Days storage at- $20^{\circ} \mathrm{C}$ & $98.56 \pm 3.33$ & $100.96 \pm 3.31$ & $99.23 \pm 4.77$ & $95.72 \pm 9.00$ & $94.23 \pm 1.92$ & $94.56 \pm 7.52$ \\
3 Freeze-thaw cycles & $99.67 \pm 3.11$ & $97.34 \pm 4.67$ & $96.45 \pm 2.16$ & $94.13 \pm 7.12$ & $94.78 \pm 7.12$ & $91.23 \pm 4.62$ \\
\hline
\end{tabular}


TABLE-4

PHARMACOKINETIC PARAMETERS OF POLYPHYLLIN II AND HYPEROSIDE AFTER SINGLE ORAL ADMINISTRATION AND CO-ADMINISTRATION OF POLYPHYLLIN II AND HYPEROSIDE EXTRACTS $(\mathrm{n}=6)$

\begin{tabular}{|c|c|c|c|c|c|}
\hline \multirow{2}{*}{ Parameters } & \multirow{2}{*}{ Unit } & \multicolumn{2}{|c|}{ Polyphyllin II } & \multicolumn{2}{|c|}{ Hyperoside } \\
\hline & & Single administration & Co-administration & Single administration & Co-administration \\
\hline $\mathrm{T}_{1 / 2}$ & $\mathrm{~h}$ & $4.43 \pm 2.60$ & $3.77 \pm 1.67$ & $4.23 \pm 1.79$ & $3.68 \pm 1.36$ \\
\hline $\mathrm{T}_{\max }$ & $\mathrm{h}$ & $3.67 \pm 0.52$ & $3.83 \pm 0.41$ & $1.67 \pm 1.67$ & $2.00 \pm 0.00$ \\
\hline $\mathrm{C}_{\max }$ & $\mu \mathrm{g} / \mathrm{mL}$ & $19.47 \pm 2.65$ & $16.30 \pm 2.69$ & $14.06 \pm 1.53$ & $11.10 \pm 1.10$ \\
\hline $\mathrm{AUC}_{0-24}$ & $\mu \mathrm{g} \mathrm{h} / \mathrm{mL}$ & $100.28 \pm 24.93$ & $83.71 \pm 14.27$ & $61.48 \pm 11.83$ & $46.50 \pm 2.69$ \\
\hline $\mathrm{AUC}_{0-\infty}$ & $\mu \mathrm{g} \mathrm{h} / \mathrm{mL}$ & $151.38 \pm 46.57$ & $128.45 \pm 35.30$ & $81.67 \pm 16.38$ & $64.46 \pm 8.00$ \\
\hline MRT & $\mathrm{h}$ & $8.10 \pm 3.47$ & $7.13 \pm 2.24$ & $6.45 \pm 1.83$ & $5.85 \pm 1.43$ \\
\hline $\mathrm{K}_{\mathrm{e}}$ & $h^{-1}$ & $0.19 \pm 0.08$ & $0.21 \pm 0.07$ & $0.19 \pm 0.06$ & $0.21 \pm 0.07$ \\
\hline
\end{tabular}

After single administration, hyperoside plasma concentration reached a maximum at $1.67 \pm 1.67 \mathrm{~h}$ with an average $\mathrm{C}_{\max }$ of $14.06 \pm 1.53 \mu \mathrm{g} / \mathrm{mL}$. The $\mathrm{T}_{1 / 2}$ was calculated to be 4.23 $\pm 1.79 \mathrm{~h}$. The area under the curve $\left(\mathrm{AUC}_{0-\infty}\right)$ was $81.67 \pm 16.38$ ( $\mathrm{h} \mu \mathrm{g} / \mathrm{mL}$ ). The mean values of $\mathrm{K}_{\mathrm{e}}$ was $0.19 \pm 0.06 \mathrm{~h}^{-1}$ and MRT was $6.45 \pm 1.83 \mathrm{~h}$. After co-administration, hyperoside plasma concentration reached a maximum at $2.00 \pm 0.00 \mathrm{~h}$ with an average $\mathrm{C}_{\max }$ of $11.10 \pm 1.10 \mu \mathrm{g} / \mathrm{mL}$. The $\mathrm{T}_{1 / 2}$ was calculated to be $3.68 \pm 1.36 \mathrm{~h}$. The area under the curve $\left(\mathrm{AUC}_{0-\infty}\right)$ was $64.46 \pm 8.00(\mathrm{~h} \mu \mathrm{g} / \mathrm{mL})$. The mean values of $\mathrm{K}_{\mathrm{e}}$ was 0.21 $\pm 0.07 \mathrm{~h}^{-1}$ and MRT was $5.85 \pm 1.43 \mathrm{~h}$.

As shown in Fig. 3, the AUC of polyphyllin II and hyperoside decreased when other components were added, while the clearance of these ingredients increased. Present work showed that hyperoside was reduced the pharmacokinetics of polyphyllin II. So, it is concluded that the depressed pharmacokinetic interactions occurred among two compounds.

Table-4 indicated that polyphyllin II and hyperoside exert the same influence on the pharmacokinetics to the each other. When hyperoside was added the $\mathrm{AUC}_{0-\infty}$ of polyphyllin II decreased by $15.14 \%$ on average. When polyphyllin II was added the $\mathrm{AUC}_{0-\infty}$ of hyperoside decreased by $21.07 \%$ on average. Present findings indicate that polyphyllin II and hyperoside have a clear effect on the pharmacokinetic behaviour.

\section{Conclusion}

In conclusion, a rapid and specific RP-HPLC-UV method was developed for the analysis of polyphyllin II and hyperoside in beagle dog plasma after oral administration of polyphyllin II and hyperoside extracts, which had high sensitivity, recovery, precision, accuracy and reproducibility. This method can be useful for the determinations of polyphyllin II and hyperoside in other bio-samples in future studies. Moreover, the pharmacokinetic parameters of polyphyllin II and hyperoside following oral dosing would be a suitable reference in clinical application. Extensive and complex pharmacokinetic interactions were observed among polyphyllin II and hyperoside. Polyphyllin II and hyperoside have a clear effect on the pharmacokinetic behaviour. Further study is needed to investigate the potential pharmacodynamic changes due to the content variation of polyphyllin II and hyperoside.

\section{REFERENCES}

1. The Pharmacopoeia Commission of PRC, Vol. 215, p. 243 (2010).

2. Y.H. Hua, S.L. Ma, Z.F. Fu, H.Z. Mou and H. Jiang, Chin. Arch. TCM, 29, 1387 (2011).

3. L.L. Yan, Y.J. Zhang, W.Y. Gao and S.L. Man, Chin. Trad. Herbal Drugs, 40, 424 (2009).

4. F. Shan, L.J. Yang, Y.F. Peng, X.R. Kang and Y.H. Ma, Chin. JMAP, 27, 961 (2010)

5. Z.W. Chen and C. Ma, Acta Pharmacol. Sin., 1, 20 (1999).

6. W.Q. Wang, C.G. Ma and X.Y. Xu, Acta Pharmacol. Sina, 4, 14 (1996).

7. J.R. Wei and J. Li, Mod. Chin. Med., 9, 26 (2007).

8. X.L. Bi, A.L. Xu and W.H. Luo, Chin. J. Exp. Trad. Med. Formulae, 16, 64 (2010).

9. Y. Ke, J. Ni and J.C. Yao, J. Beijing Univ. Trad. Chin. Med., 8, 555 (2006). 